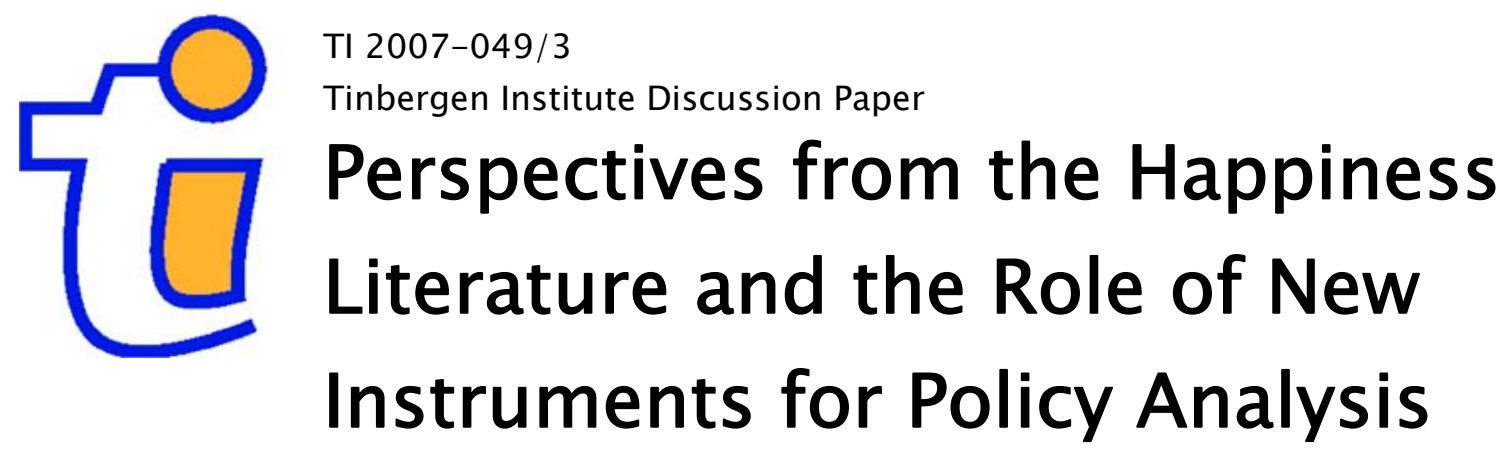

Bernard M.S. van Praag 


\section{Tinbergen Institute}

The Tinbergen Institute is the institute for economic research of the Erasmus Universiteit Rotterdam, Universiteit van Amsterdam, and Vrije Universiteit Amsterdam.

Tinbergen Institute Amsterdam

Roetersstraat 31

1018 WB Amsterdam

The Netherlands

Tel.: $\quad+31(0) 205513500$

Fax: $\quad+31(0) 205513555$

Tinbergen Institute Rotterdam

Burg. Oudlaan 50

3062 PA Rotterdam

The Netherlands

Tel.: $\quad+31(0) 104088900$

Fax: $\quad+31(0) 104089031$

Most TI discussion papers can be downloaded at http:/ /www.tinbergen.nl. 


\title{
Perspectives from the Happiness Literature and the Role of New Instruments for Policy Analysis
}

\author{
Bernard M. S. van Praag*
}

\begin{abstract}
After having been ignored for a long time by economists, happiness is becoming an object of serious research in 21st century economics. In Section 2 we sketch the present status of happiness economics. In Section 3 we consider the practical applicability of happiness economics, retaining the assumption of ordinal individual utilities. In Section 4 we introduce a cardinal utility concept, which seems to us the natural consequence of the happiness economics methodology. In Section 5 we sketch how this approach can lead to a normative approach to policy problems that is admissible from a positivist point of view. Section 6 concludes. (JEL codes: B21, B41, D63, I31, I38)
\end{abstract}

Keywords: Happiness economics, subjective well-being, equivalence scales, economic policy.

\section{Introduction}

During the last years we see a small revolution in economic science. I have in mind the rise of "happiness economics" as a serious branch of economics. Until quite recently the concept of "happiness" as a research subject for economists was anathema. The aim of this article is a consideration of the relevance of this new development in economic science for economic science as such and for economics as a tool for policy making.

The fundamental aversion among twentieth-century economists towards the concepts of happiness, well-being, ${ }^{1}$ etc. may be traced back to the influence of Behaviourism in general and the influential tract of Robbins (1932) in particular. ${ }^{2}$

Although Robbins recognized that psychology plays a role in the explanation of economic behaviour, he excludes the idea that feelings, and especially feelings of happiness, could be measured in an operational way. As we assume that economic behaviour, that is making choices between alternatives, is motivated by maximization of utility, satisfaction, well-being or happiness, ${ }^{1}$ this stand leaves the economist in an

* Bernard M.S. van Praag is affiliated to University of Amsterdam, e-mail: B.M.S.vanPraag@uva.nl

1 We will make no difference between those notions. The reason therefore is that all those notions are metaphysical concepts. Without an operational measurement method they remain empirically indistinguishable.

2 I will refer to the second printing.

(C) The Author 2007. Published by Oxford University Press

on behalf of Ifo Institute for Economic Research, Munich. All rights reserved.

For permissions, please email: journals.permissions@oxfordjournals.org 
awkward position. He observes only the results of a choice process, but he does not observe the underlying components of the choice process. In terms of the traditional consumer model, he observes only the preferred commodity bundle, but not the indifference curves behind it. Happiness economics makes an attempt to observe and estimate the indifference curves on a space of alternatives. Such a space may involve various combinations of income, family size, health, etc. The same method could theoretically be applied to assess the shape of indifference curves on the traditional commodity space. As far as we are aware of, this has not been done yet.

Since at least from Pareto (1909) economists differentiate between ordinal utility and cardinal utility. Mainstream economists mostly do not talk of happiness but of utility. As we said before, the choice of the word is just a matter of taste without consequences. We may also talk of ordinal and cardinal happiness. Ordinal utility/happiness is just a labelling system for indifference curves, where a higher label corresponds to a higher utility level. If three indifference curves in a space of alternatives are labelled $1,2,3$, respectively, it implies that the individual is indifferent between alternatives with the same label, that is on the same indifference curve, while 1-alternatives are considered as worse than 2-alternatives and 3 -alternatives as better than 2-alternatives. The curves may be relabelled as $2,2 \frac{1}{2}$ and 5 without any consequences. In the case of a cardinal utility/ happiness interpretation the re-labelling has consequences. In the first labelling system the utility differences between the three curves were equal, while in the second labelling system the utility difference between the first two is slight, while the difference with the third is considerable. Let us assume a population of three persons, one on each curve. In the first system average utility/happiness would be 2 and in the second labelling system $3 \frac{1}{6}$. It is obvious that for a meaningful evaluation of average or national happiness or for the inequality in the happiness distribution the additional assumption of cardinality is essential.

In the early economic literature there was a definite cardinal flavour (e.g. Marshall, Pigou). Economics as part of the social sciences was assumed to play a role in the solution of social problems, e.g. the alleviation of poverty and inequality, the promotion of employment and economic growth. Just taxation implied a comparison between individuals of losses in happiness caused by the imposition of taxes. Even if classical economists were unable to assess happiness and differences in cardinal happiness empirically, there was some perspective that in the future this might become possible. Since Robbins' (1932) influential tract, the assumption of cardinal utility fell gradually into discredit. It got the seemingly final blow by Samuelson (1947) and Houthakker $(1950,1961)$ with their "revealed preferences" approach and the ensuing erosion of the utility concept. 
Actually, this development of economic science over the last 60 years is a mixed blessing. By the erosion of the utility concept and the denial of a cardinal character to the utility concept economic science lost much of its relevance for practical socio-economic policy, which deals for a large part with distribution problems requiring comparisons of utility or happiness between individuals. Prudent economists do not dare to call one distribution not worse than an alternative distribution, except if that distribution is not worse than the alternative for all individuals involved. For example, no one will have qualms when stating that an income distribution between two persons $y^{(1)}=(3000,2000)$ is better than $y^{(2)}=(2000,1000)$. The first situation is better in the sense of Paretooptimality. However, at the same time this is a rather trivial statement. In most cases where distributions or social situations have to be compared we do not meet this simplistic situation. It is only possible to say that some people are better off in one situation than in the other and that the inverse statement holds for other people involved. Hence, we cannot make a statement about the ranking of the two situations in terms of social desirability.

If economists are declaring themselves unable to make normative evaluations and comparisons, at the same time they declare themselves unable to offer help for most political decision situations, which as a matter of fact are and can only be based on such comparisons.

It seems that theoretical mainstream economics has chosen for the more prudent, let us say, scientific position, sticking to Pareto-optimality as the ultimate tool, in this way reducing (perhaps rightly) the ambition of economics to be a policy instrument.

However, it is not exaggerated to notice here a certain schizophrenia, hidden in many economists. On the one hand in theoretical work they detest to make normative statements, while in their applied work they do it as a matter of routine. But even in many "pure" fields of economics we find hidden normative judgements. For instance, the literature on the construction of income inequality measures on an axiomatic basis is full of hidden normative statements. For instance, the Dalton axiom that says that income inequality is reduced by transferring money from a rich person to a poor one is based on a normative vision (however, sympathetic) on interpersonal utility comparison and the validity of Gossen's First Law, never scientifically shown to be true.

The question we would like to tackle here is whether the new "happiness economics approach" offers new perspectives for economics as a science and for its application in economic and social policy. Our reaction will be in the affirmative.

The structure of this article is as follows. In Section 2 we sketch the present status of happiness economics and we link it with the earlier 
approach in the seventies of the last century known as the Leyden School (LS). In Section 3 we consider the practical applicability of happiness economics, retaining the assumption of ordinal individual utilities. In Section 4 we introduce a cardinal utility concept, which seems to us the natural consequence of the happiness economics methodology. In Section 5 we sketch how this approach can lead to a normative approach to policy problems that is admissible from a positivist point of view. In Section 6 we draw some conclusions.

\section{What is happiness economics?}

Let us start to consider what happiness economics is. The underlying principle is simple and intuitively plausible. If you like to know how happy an individual is with "something", a straightforward method to get an idea about it is to ask an individual about his happiness with that "something". As happiness is a rather emotionally laden word, in practice we ask how "satisfied" an individual is.

The point of departure are so-called "satisfaction questions" like

How satisfied are you with your income?

How satisfied are you with your job?

How satisfied are you with your health?

How satisfied are you with your life as a whole?

Those questions have been posed in psychological surveys for quite some time.

The discrete response is either in terms of verbal categories like "horrible", "bad", ...,"not bad", "delighted" or in numerical categories like $1,2, \ldots, 5$ or $0,1,2, \ldots, 10$.

It is now generally accepted that such questions make sense. More precisely, most respondents are willing and are able to answer such questions, and respondents in similar circumstances give similar responses. As shown before, such questions may refer to many different things, like in this example "income", "job", "health" or "life- as a whole". It may be aspects of life, or as psychologists say "life domains".

Up to this moment the response is nearly always discrete, although conceptually a continuous response scale is possible as well. In the latter case we may think of a continuous line interval from A (worst) to B(best), where respondents put a cross at the point that corresponds with their feeling on a (worst,best) scale.

Modern satisfaction researchers or "happiness economists" are not only interested in observing the degree of satisfaction with different "domains of life" and in being able to state that in the EU average satisfaction with 
income is a 7 on a 10-scale and in Russia a 5. They are interested in the question why one person is satisfied to such and such a degree with a specific life aspect or life "domain". Their primordial research question may be summarized as: What are the determinants of satisfaction?

The basic methodology to assess the influence of different factors $x$ is to assume a latent utility variable $\mathrm{u}$ for which holds $u=f(x ; \beta, \varepsilon)$, where $\beta$ is a parameter vector and $\varepsilon$ a random disturbance term. It is assumed that all respondents that give the same response enjoy the same utility/happiness value $u$. That is, they are situated on the same indifference curve in an ordinal context. The most simple model is then to use a linear description and to assume for respondent $n$ that $u_{n}=\beta_{1} x_{1, n}+\beta_{2} x_{2, n}+\cdots+\beta_{0}+\varepsilon_{n}$. Such a model with discrete response is traditionally estimated by Ordered Probit or Ordered Logit. The equation $\beta_{1} x_{1}+\beta_{2} x_{2}+\cdots+\beta_{0}=$ constant describes an indifference surface and the ratios $\beta_{i} / \beta_{j}$ are the trade-off coefficients between the factors $x_{i}$ and $x_{j}$. It is mostly possible to assess the shadow price of a variable $x$. Let us assume $x_{2}$ stands for income and $x_{1}$ is changed into $x_{1}+\Delta x_{1}$. If that increase is happiness increasing and if more income is also preferred to less income, then the change into $x_{1}+\Delta x_{1}$ has to be compensated by an income decrease $\Delta x_{2}$ such that the individual stays on the same indifference curve. More exactly, we require $\beta_{1}\left(\Delta x_{1}\right)+\beta_{2}\left(\Delta x_{1}\right)=0$, yielding a shadow value $\left(\beta_{1} / \beta_{2}\right)\left(\Delta x_{1}\right)$.

The beginning of happiness economics is frequently set in the beginning of the nineties (see Frey and Stutzer 2002). That is not entirely true. The work of the so-called LS in the seventies of the previous century, named after the Dutch university to which the research group was affiliated, can be seen as part of happiness economics as well, although in the beginning of the seventies the word "happiness" was avoided by the LS in favour of the less presumptuous term "individual welfare of income". It is interesting to line out what are the differences and similarities between the LS-approach and the contemporary happiness approach (CHS). This is not only interesting from a scientific historical perspective. It might be that LS has things to offer that fill in a lacuna in contemporary happiness economics. Moreover, there seems to be some confusion among modern happiness economists about the question in how far the old Leyden School was on the same track. Therefore, we shall firstly devote some lines on the LS-approach.

In 1968 I published my book on Individual Welfare functions and Consumer Behavior. One of its main theses was that utility or welfare might be an operational and measurable concept. In Van Praag (1971), challenged by some empirical opportunities, I formulated the so-called Income Evaluation Question (IEQ). It was a question module by which something should be measured, that I called welfare derived from income. The idea was that only by questioning the individual himself we might be 
able to get information about his feelings on welfare (happiness, etc.). This idea of asking people about their feelings and accepting this as valuable information is a basic and common point of departure for LS and CHS. In 1971 most economists did not accept this simple truth, denying themselves by this refusal very valuable information.

The IEQ, has been posed in the years since then to many thousands of respondents. It runs as follows:

The Income Evaluation Question (IEQ) (mid-interval version)

Whether you feel an income is good or not so good depends on your personal life circumstances and expectations.

In your case you would call your net household income:

a very low income if it would equal $€$

a low income if it would equal $€$

a still insufficient income if it would equal $€$

a just sufficient income if it would equal $€$

a good income if it would equal $€$

a very good income if it would equal $€$

The differences between this IEQ and modern satisfaction questions can be summarized as follows:

(i) The IEQ deals with income, that is with financial satisfaction only. Satisfaction questions may deal with financial satisfaction, job satisfaction, life as a whole, etc. Hence, we have to compare the IEQ with the financial satisfaction (FINSAT)-question.

(ii) The FINSAT-question asks for an evaluation of current income $y_{c}$. This is so to say the stimulus to the respondent. The respondent's reaction is an evaluation on a numerical or verbal evaluation scale. The IEQ provides six stimuli $U_{1}, \ldots, U_{6}$ in terms of evaluations on a verbal evaluation scale. The six reactions of the respondent are denoted by $c_{1}, \ldots, c_{6}$. There are two possibilities to utilize the results provided by the IEQ: an ordinal and a cardinal one.

(iii) In the ordinal representation we compare answers $c_{i, n}$ by different respondents $n$ with different individual characteristics $x_{n}$. As the respondents with different characteristics are observed to need different income levels $c_{i, n}$ to reach the same FINSAT-level $i$, we may look for a relationship $c_{i} n=\beta_{1} x_{1, n}+\beta_{2} x_{2, n}+\cdots+\beta_{i}+\varepsilon_{n}$. For fixed $i$ it describes an indifference curve for the level $i$. (see, e.g. Van Praag and Van der Sar 1988). 
(iv) In the cardinal interpretation the LS translated the verbal evaluations $U_{1}, \ldots, U_{6}$ into numbers $\frac{1}{12}, \frac{3}{12}, \ldots, \frac{11}{12}$. That this is a reasonable way of translating words into numbers in this context, is empirically confirmed in Van Praag (1991). Then a log-normal distribution function $U_{n}(c)=\Lambda\left(c ; \mu_{n}, \sigma_{n}\right)$ was fitted through the points $\left\{\left(c_{i n},(2 i-1 / 12)\right)\right\}_{i=1}^{6}$. The individual parameters $\mu_{n}, \sigma_{n}$ are estimated $^{3}$ by the log-mean and the log-standard-deviation of the responses $c_{1 n}, \ldots, c_{6 n}$. It follows that by means of the IEQ an individual utility function (or in the LS-terminology an individual welfare function) $U_{n}(c)$ can be estimated for each separate individual. As $\mu_{n}, \sigma_{n}$ differ over individuals those utility functions are different.

(v) The individual parameter $\mu_{n}$ (like the separate answers $c_{1 n}, \ldots, c_{6 n}$ ) can be well explained by individual characteristics $x_{n}$, including current income $y_{c}$. As the coefficient of income is significantly positive, it implies that someone's utility function shifts with increasing income. More precisely, financial needs increase with a rise of current income. This shift of norms with respect to income with the individual situation was called in van Praag (1971) preference drift. It is the same adaptation phenomenon that the psychologists Brickman and Campbell (1971) discovered in the same year in another context and empirical setting. They called it the hedonic treadmill. The own situation serves as an anchor point; if the own situation changes norms about satisfaction will shift accordingly.

(vi) As it is empirically found that $U_{n}(c)=\Lambda\left(c ; \mu_{n}\left(y_{c}\right), \sigma_{n}\right)$, it is easy and attractive to estimate how individual $n$ evaluates his current income. There holds $U_{n}\left(y_{c}\right)=\Lambda\left(y_{c} ; \mu_{n}\left(y_{c}, x_{n}\right), \sigma_{n}\right) \stackrel{\text { def }}{=} \tilde{U}\left(y_{c} ; x_{n}\right)$. The last term is the true evaluation by an individual of his own income. Hence, already in the LS (see, Van Praag 1971) there was made a distinction between an ex ante welfare function, which describes how a specific individual evaluates all income levels and an ex post welfare function, which describes how all members of the population evaluate their own income. Here there is some analogy with the distinction between decision utility and experienced utility, made by Kahneman, Wakker and Sarin (1997).

(vii) The link between LS-results and CHS-results lies in the fact that the Leyden ex post welfare function is identical to the financial satisfaction function, that is, it has the same indifference curves. It implies that for financial satisfaction the same tradeoffs are found as when using the financial satisfaction question.

3 In the early LS-publications a slightly different method was used to estimate $\mu$ and $\sigma$; later on the log-mean and log-S.D. appeared to give almost identical results. 
Then it is no wonder that many of the LS-results can be found back in the MHS-literature, e.g. for the effect of reference groups, external effects, family size, etc. We refer to Van Praag and Ferrer-iCarbonell (2004) for an extensive review. Earlier reviews may be found in Van Praag (1976, 1993, 1999).

(viii) Although in most of the Leyden literature the parameter $\mu$ is derived in a cardinal context, the parameter itself makes also sense in an ordinal context. Most Leyden results do not need that cardinal interpretation and keep their validity in an ordinal environment (cf. Van Praag, Van der Sar, 1988). The cardinality assumption is only essential for the analysis of inequality and redistribution problems.

(ix) In sum, the LS-literature is based on a somewhat more demanding question module. It deals only with financial satisfaction, while CHS deals with various domains and global welfare/happiness. In the domain of financial satisfaction it gives the same results as CHS, while the very useful distinction between ex ante and ex post evaluations is added.

Although the LS provided remarkable results and got some sympathizers all over the world, the truth is that it was never accepted by mainstream economics, because mainstream economics in the seventies maintained that such measurements were impossible in the first place. Sociologists and psychologists mostly did not know of the results, because those results were not submitted to their journals and in those days there reigned a terrible provincialism between the behavioural sciences, where sociologists and psychologists strictly rejected the idea that economists could have to offer something meaningful on the subject of "feelings".

Somewhat later, also independently, Easterlin (1974) as a rare exception in those times studied happiness and discovered the famous Easterlin paradox, saying that differences in individual happiness between citizens within a country may be explained for a good deal by differences in material circumstances, while he found average reported happiness to be about the same in some strongly different countries, poor and rich all over the world.

\section{The practical applicability of happiness economics, retaining the assumption of ordinal individual utility}

In the previous pages we noticed already that satisfaction responses may be (partly) explained by objective factors $x$. Now we shall pursue this line. 
The resulting outcomes of the satisfaction questions in surveys may be summarized by satisfaction distributions, as shown in Table 1, which we derived from the German Socio-Economic Panel (GSOEP). For instance, $10.93 \%$ evaluate their job by " 5 ", $18 \%$ by " 7 " and about $28 \%$ by " 8 ". For other domains of life we find other evaluations.

If such job evaluations are meaningful responses, we have to assume that the $18 \%$ respondents who evaluate their job situation by a 7 have about the same feeling of satisfaction with respect to their job. It cannot be that a "7" means for one respondent "very good" and for another "very bad". This is a not unreasonable assumption for respondents who have about the same cultural and linguistic background. However, let us realize that this assumption cannot be proven to be true, for, therefore, we would need some kind of psychometer, which tells us by psychophysical means how satisfied one is. Hence, the "common background"assumption is a primitive assumption. However, it is an assumption, which is tacitly accepted in nearly all empirical surveys. This assumption is also called the assumption of interpersonal comparability of satisfaction. Clearly, this assumption is not strange at all except for the most extreme economic curmudgeons. ${ }^{4}$ Most humans will be in no doubt when they see somebody laughing or smiling; they will interpret it as a person in a happy mood. Alternatively, when we see a weeping or frowning person we will interpret it as that the person is unhappy. We interpret such signs of moods similarly and we are also able to identify those feelings of the other in terms of own feelings. The same holds for the interpretation of wordings in a questionnaire.

If we assume interpersonal ordinal comparability to be a valid assumption, our data set can be split up into categories $0,1, \ldots, 10$ of respondents who belong to the same satisfaction class. For the time being we do not assign yet a cardinal significance to those satisfaction levels, that is, we do not assume that a respondent belonging to class 8 feels twice as happy as one belonging to class 4 . However, we observe that two respondents, who are in objectively different circumstances, may be equally happy, for they evaluate their situation by the same response. They are situated on the same indifference curve.

Now we shall consider how such a data set may be used for policy making. We focus as an example on the effect of family size on financial satisfaction. Notice, however, that this is just intended as an example of a general method. Subsequently, we will point to some other applications. Our example will deal with the satisfaction with income, or financial

4 The definition is according to the dictionary: An ill-tempered person full of resentment and stubborn notions. 


\begin{tabular}{|c|c|c|c|c|c|c|c|c|c|c|c|}
\hline & 0 & 1 & 2 & 3 & 4 & 5 & 6 & 7 & 8 & 9 & 10 \\
\hline Job Sat. & 0.80 & 0.55 & 1.73 & 3.04 & 4.32 & 10.93 & 9.96 & 17.97 & 27.89 & 13.81 & 9.0 \\
\hline Financ. & 0.31 & 0.33 & 0.77 & 1.89 & 3.46 & 9.35 & 10.62 & 22.19 & 30.10 & 13.46 & 7.53 \\
\hline Health & 0.68 & 0.54 & 2.03 & 3.59 & 4.51 & 12.13 & 10.11 & 17.49 & 26.06 & 13.25 & 9.62 \\
\hline Housing & 0.93 & 0.50 & 1.51 & 2.49 & 3.50 & 7.89 & 7.68 & 14.85 & 25.72 & 17.87 & 17.06 \\
\hline Leisure & 1.02 & 1.33 & 3.57 & 5.49 & 6.32 & 13.68 & 11.51 & 16.86 & 21.40 & 10.01 & 8.81 \\
\hline Envir. & 0.81 & 0.71 & 1.78 & 4.73 & 6.64 & 16.95 & 14.56 & 22.15 & 20.29 & 7.68 & 3.69 \\
\hline General & 0.23 & 0.25 & 0.71 & 1.35 & 2.76 & 9.72 & 11.07 & 23.98 & 33.51 & 11.63 & 4.77 \\
\hline
\end{tabular}


satisfaction FINSAT.This point is illustrated by Figure 1. Let us assume that we find from our (financial) satisfaction question that family ${ }^{5} A$ with a monthly income $y=€ .2000$ and no children $\left(f_{s}=0\right)$ is equally satisfied with its financial situation as family $B$ with an income $y=€ .3000$ and two children $(f s=2)$. Or in formula $(2000,0) \sim(3000,2)$, where the sign " $\sim$ " has to be read as "equally satisfied". This observation leads straight ahead to a political recipe for the construction of a family equivalence scale.

Assume that the government looks for an answer to the question how much family allowance we should give to a family $C$ with income $y=€ .2000$ and two children $(f s=2)$, in order that it will be at the same satisfaction level as family $B$. It stands to reason that the financial situation of family $C$ is evaluated less than that of the family $A$ with $€$.2000, since family $C$ has two additional children to support. In order that $A$ and $C$ feel equally satisfied the family $C$ should get an income increase of $€ 1000$ in order to arrive at the same curve as $A$. In fact, the first two families $A$ and $B$ are situated on the same "satisfaction indifference"- curve, while family $C$ is situated on an indifference curve corresponding to a lower satisfaction level. A few of those indifference curves are sketched in Figure 1.

We see that an increase in family size $f s$ has to be compensated by an increase in income $y$ in order to keep the family at the same level of financial satisfaction as before the family size increase took place. This is what economists call the compensating income. If this compensation is not given, the family shifts to a lower satisfaction level, which corresponds in Figure 1 to a higher curve.

The family compensation to generate equality is $€ 1000$, If we compensate by less, say $€ 500$, then the family will be under-compensated. Would we like to compensate by more, say $€ 1500$, the family would be over-compensated.

The amount of $€ 1000$ is what Kapteyn and Van Praag (1976) called a welfare-neutral family compensation. What we do not know, if we stick to the ordinal interpretation, is: how serious is the welfare difference caused by the $€ 500$ under-compensation? Is the emotional difference slight or even negligible, or is the under-compensation really painful?

Obviously, the government does not have to follow the rule of welfareneutrality in practice. It may be that policy makers willingly prefer to overcompensate low-income families and to under-compensate high-income families for political reasons. Then the political instrument of the family assistance schedule is an instrument to change the distribution of income

5 We do not dwell here on the difference between the satisfaction of an individual and that of a household/family. 


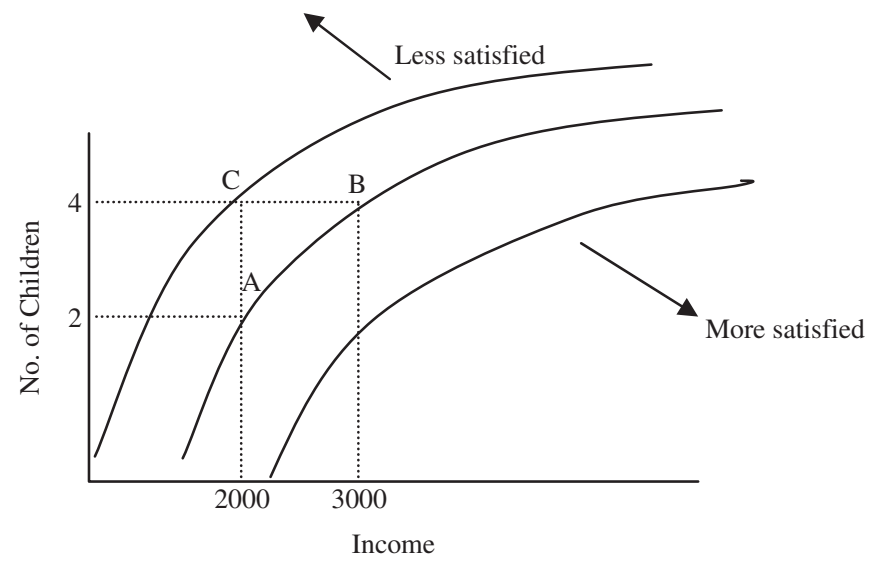

Figure 1 FINSAT-Indifference curves in ( $f s$, income)-space

and indirectly that of happiness. But, the welfare neutral scheme is at least a benchmark for policy makers to find out in how far the enacted schedule satisfies welfare neutrality and to see which income classes are over-compensated or under-compensated.

As we suggested already, the crux of the matter is whether those indifference curves are estimable. The answer is yes. We may derive such curves from the answers on satisfaction questions, where the basic assumption is that individuals, who state that they belong to the same satisfaction response category, by definition are situated at the same indifference curve. The technical methodology is at this place beyond the scope. Let it suffice to say that the methodology has now been facilitated so much, also by means of standard software now available, that any economist or other social scientist with a slight knowledge of statistics and computer programming can perform such estimations. Actually, there are different variants of the method, e.g. Probit or Logit regression. As Ferrer-i-Carbonell and Frijters (2004) have shown, the many experiences thus far yield remarkably stable and robust results, which only marginally depend on the specific method applied. In Van Praag and Ferrer-i-Carbonell $(2004,2006)$ it has been shown that simple OLS-variants may be constructed that are as good as Probit or Logit, but computationally much easier and faster to implement than the traditional methods. A moment of thought explains much of this robustness. All these specifications amount to different specifications of the labelling system of the underlying indifference curves, but the indifference curves themselves are unchanged and it is these indifference curves which are estimated, either by Ordered Probit, Logit or what else.

The family equivalence scale derived from data from the GSOEP is tabulated in Table 2. We see that a couple with one child would need 
Table 2 Family Equivalence Scales, derived from financial satisfaction questions

\begin{tabular}{lc}
\hline Household size & Correction factor \\
\hline 1 & $81 \%$ \\
2 & $100 \%$ \\
3 & $113 \%$ \\
4 & $123 \%$ \\
5 & $132 \%$ \\
6 & $140 \%$ \\
7 & $146 \%$ \\
8 & $152 \%$ \\
\hline
\end{tabular}

(from VanPraag and Ferrer-i-Carbonell 2004, Table 2.3)

$13 \%$ more of net income in order to be at the same financial satisfaction level as the couple without child.

The real significance of this method becomes clear when we compare it with the traditional methods to define a family equivalence scale (see Van Praag and Warnaar 1997). The most traditional method in economic literature is to assess the cost of children by means of budget analysis or by means of normative budgets, defined by nutritional experts. The latter approach is clearly paternalistic, as it depends on the opinion of a commission of experts. The former approach derived from demand analysis is based on assumptions, which are more or less arbitrary. For instance, that it would be possible to distinguish specific commodities and services as "adult goods" (Deaton and Muellbauer 1986). Then two families of different size are assumed to be at the same welfare level if they have the same consumption of adult goods. There are two basic problems with this method. First, what are adult goods: alcoholics, cigarettes, a haircut? The second point is that a couple with a child may have a completely different consumption pattern as a couple without adults without being less or more satisfied. It is probable that most parents will drink less than couples without child, but would that imply a lower level of satisfaction? The basic problem, however, is that equivalence can only be defined if we know or can observe when individuals are equally satisfied. The only way in which we can find this out is by asking people how satisfied they are and by assuming that individuals who use the same expression in order to express their level of satisfaction are equally satisfied. The adult good approach or any other approach that is not based on this simple observation must be seen as arbitrary (see for a more detailed analysis, Van Praag and Warnaar 1997).

It is obvious that the satisfaction approach is also less exact than it looks like and has many limitations we need to be aware of. 
First, satisfaction may vary on a continuous scale. If we observe it discretely in terms of a few response categories, a loss of accuracy is incurred. Moreover, satisfaction methods assume a model as well, which may be more or less realistic. For instance, the equivalence scale tabulated in Table 2 has been based on a model equation

$$
u_{i}=\alpha \ln (f s)+\beta \ln (y)+\gamma
$$

where $i$ stands for a specific response category, that is, level of financial satisfaction. This is actually the equation describing the satisfaction indifference curve of level $i$.

In the log-case an increase by $\Delta \ln (f s)=\ln (f s)-\ln \left(f_{s_{0}}\right)$ has to be compensated by an income increase

$$
\left[\ln (y)-\ln \left(y_{0}\right)\right]=\frac{\alpha}{\beta}\left[\ln (f s)-\ln \left(f_{s_{0}}\right)\right]
$$

This specification is the basis for Table 2 . We see that the compensation depends on the initial family size $f_{s_{0}}$, where we have a "cheaper by the dozen"-effect (due to the lgogartihmic specification of family size), and on the initial income level $y_{0}$, which implies that richer people get more compensation in absolute amounts than poorer people.

Who says that this is the correct equation?

One of the problems with this equation is that the resulting incomecompensation schedule depends on the initial income level. It is a fixed percentage of income. Let us now consider the alternative equation where logarithms have been replaced by absolute values:

$$
u_{i}=\alpha \cdot f s+\beta \cdot y+\gamma
$$

For the linear case the income compensation is given by

$$
y-y_{0}=\frac{\alpha}{\beta}\left[f s-f_{s_{0}}\right]
$$

In this case there is no "cheaper by the dozen"-effect; each additional child is compensated for by the same money amount.

The model equation

$$
u_{i}=\alpha \cdot \ln (f s)+\beta \cdot y+\gamma
$$

would yield a compensation

$$
y-y_{0}=\frac{\alpha}{\beta}\left[\ln (f s)-\ln \left(f_{s_{0}}\right)\right]
$$

Here poor and rich people would get the same compensation, but the "cheaper by the dozen"-effect is maintained. 
It follows that the choice of the model equation is rather crucial with respect to the resulting compensation schedule.

A second point is whether the indifference curves are parallel or that they are specific for the level $i$ of satisfaction reached. Or in formula,

$$
u_{i}=\alpha_{i} \ln \left(f_{s}\right)+\beta_{i} \ln (y)+\gamma_{i}
$$

In that case the compensation schedule changes with the level of satisfaction. This might entail that rich people with a high level of satisfaction might have a smaller trade-off ratio $\alpha_{i} / \beta_{i}$ than poor people. Indeed, there is evidence found for this case (see Van Praag and Ferrer-i-Carbonell 2004).

A third complication is caused by the question whether financial satisfaction is only depending on the variables family size $f s$ and net income $y$ or that there are other variables relevant as well, e.g. region, age, price level.

Certainly there are omitted but relevant variables. On top of that there is a random disturbance term, standing for all unobservable variables like individual psychological traits. We can use panel data models to control for individual psychological traits that typically do not change across time, for example optimism and intelligence. Nevertheless, we cannot control for those traits that change across time. For example, individual's capacity to adapt by changing expectations.

It follows that this satisfaction approach is also not without difficulties. However, these specification and choice of variables difficulties are shared by both the traditional and the subjective satisfaction approach. Eventually, it depends on subjective choices, made by the researcher and sometimes by politicians, who like to get politically feasible results.

But there is an essential difference between the traditional methods and this subjective satisfaction approach. The traditional approach begins with a naïve artificial criterion to answer whether families are at the same satisfaction level or not. In the subjective approach this is not necessary, as satisfaction equality can be empirically observed. If two respondents are equally satisfied, they will evaluate their satisfaction with the same value, either numerically or verbally. This opens the way to find empirically which equation and combination of variables fits the data, i.e. the responses on satisfaction questions, best.

It is evident that the same methodology may be used to assess the effects of other variables on FINSAT.

Up to now we have exclusively considered the relation between financial satisfaction FINSAT and the size of the family. However, it is possible to apply the same methodology to the satisfaction with other domains of life, like job satisfaction, health satisfaction or satisfaction with life as a whole. 
At first researchers were interested in determinants such as income, unemployment (Clark and Oswald 1994), etc. Later on, the focus expanded to the effects of reference groups (Ferrer-i-Carbonell 2005; Luttmer 2005), inflation (Boes, Lipp and Winkelmann 2007), and to policy oriented issues such as health economics (Ferrer-i-Carbonell and Van Praag 2002), environmental issues like airport noise (Van Praag and Baarsma 2005).Then the range of topics widens more and more to include crime and terrorism (Frey, Luechinger and Stutzer 2004).

Clark, Oswald and Warr (1994) looked at job satisfaction and how it varies with age. They found that job satisfaction is U-shaped in age. Many other studies using other data sets seem to confirm this. Job satisfaction, as many domain satisfactions and life satisfaction, seems to reach a minimum around an individual middle age after which point satisfaction increases together with age. The only exception is health satisfaction, which shows a negative relationship with age for any age (see Ferrer-i-Carbonell and Van Praag 2004).

Di Tella et al. (2001) and Blanchflower and Oswald (2004) looked at the effect of unemployment on life satisfaction.

Frey and Stutzer (2000) looked at the impact of more or less democracy on life satisfaction, based on differences in regional government in the Swiss cantons. They found that individuals living in more democratic cantons were happier under ceteris paribus conditions.

Ferrer-i-Carbonell and Van Praag (2002) give an example where the monetary counter-values of losses in health, caused by various chronic diseases, are assessed.

Van Praag and Baarsma (2005) evaluate the damage by airplanes, caused by various noise levels on inhabitants in the neighbourhood of Amsterdam Airport. They found that airplane noise damage could be compensated by giving the inhabitant about $2 \%$ of income as a compensation subsidy.

Senik (2004), Ferrer-i-Carbonell (2005) and Luttmer (2005) investigate the effect of the neighbours' income on individual satisfaction. The reference effect was investigated by the LS as well with similar empirical outcomes. It was then called reference drift (see, Kapteyn 1977; Van Praag, Kapteyn and Van Herwaarden 1979; Kapteyn and Van Herwaarden 1980).

To these examples we might add many others from the now flourishing happiness literature. This method has been applied in many papers.

One striking paper is that by Clark and Oswald (2002). They calculate the impact of different life events upon human well-being. According to that paper "getting married, for instance, is calculated to bring each year the same amount of happiness, on average, as having an extra $£ 70000$ of income per annum. The psychological costs of losing a job greatly exceed 
those from the pure drop in income. Health is hugely important to happiness. Widowhood brings a degree of unhappiness that would take, on average, an extra $£ 170000$ per annum to offset."

Actually, the production of new papers and new results is so large during the last years that it is simply impossible to do justice to all authors and their valuable contributions. One of the recent surveys (Clark, Frijters and Shields 2006) states

Studying the causes and correlates of human happiness has become one of the hot topics in economics over the last decade, with both the size and depth of the literature increasing at an exponential rate (Kahneman and Krueger, 2006). To illustrate, a search of ECONLIT for journal articles with either "Happiness", "Life Satisfaction" or "Well-being" in the title, identifies 465 published articles between 1960 and 2006. Of these $363(78 \%)$ have been published since 1995, $285(61 \%)$ have been published since 2000 and one-third of the literature $(37 \%$, or 173 articles) has appeared in print in just the last three years. Focusing only on the period 2000-2006, this measure of economists' interest in the "economics" or "science" of happiness places that interest at roughly half the level of interest in "Wages" and just below that in "Discrimination". However, happiness is quickly catching up: it is in its "industrial revolution" stage....

Consequently, we refer to the surveys by Di Tella and MacCulloch, (2006), Clark, Frijters and Shields (2006), Frey and Stutzer (2002), Senik (2005), Layard (2005), Dolan (2006), Van Praag and Ferrer-i-Carbonell (2004) for more information.

Our conclusion is that this methodology offers a viable way to assess the monetary costs and the compensation amounts needed to neutralize specific effects of changes in satisfaction determinants plus other interesting insights such as the extent of poverty, and the effect of relative income and economic growth. We notice in passing that most of the studies cited do not take into account the mechanisms of preference and reference drift/Hedonic treadmill and comparison income. As both mechanisms combined nearly neutralize income changes, the long-term effects of monetary compensations become questionable. However, we observe that for most problems there do not exist any other viable methods.

This makes the new methodology extremely attractive for the study of policy problems.

Finally, there are domains for which income is not a significant determinant of satisfaction. An example is health satisfaction, where the income coefficient $\beta$ was found not to differ from zero. In such a case the trade-off ratios in terms of additional income cannot be calculated. 
More or less money has no influence on satisfaction. In such situations the model remains politically relevant, if compensation can be given in other determinants, i.e. less working hours, or more safety in the streets.

\section{The step to cardinality}

Up to this point we have stuck to the ordinality assumption. That is, we assume that an evaluation of an " 8 " compared to a " 7 " indicates that the individual evaluates the first situation as better than the second. However, we do not know how much better. As already said, economists have always been reluctant to make the step from ordinality to cardinality. This was caused by the strictly behaviouralist approach, where one looks only at revealed preference behaviour. That point of view admits only the following statement. If alternative $A$ is chosen above alternative $B$, it implies that satisfaction, anticipated from $A$ is more than that of $B$, but it does not yield information about the value of the difference. Is alternative $A$ "slightly preferred to" or "enormously better" than $B$ (see also, Van Praag and Frijters 1999)?

For policy making this is a really nasty situation. First, if we like to compare the average happiness of populations (see, e.g. Easterlin 1974); Blanchflower and Oswald 2004) this is strictly impossible if we adhere to the ordinal point of view. Let us demonstrate this with the following simple example. Let us assume we have two individuals. One is stating his happiness is 6 and the other evaluates his happiness by 7 . The average is 6.5. If we give only ordinal significance to these answers, we may, according to the definition of ordinality, apply any monotonic transformation to the happiness values. Let us take the simple transformation of adding 1 to all values, so that the average becomes 7.5. It shows that taking average happiness as an index of the happiness of a population (in this case just two persons) becomes meaningless. Or put otherwise, all papers and authors, to begin with the famous and important paper by Easterlin (1974), who present such averages, are implicitly embracing $a$ cardinal interpretation, even if they do not mention this explicitly. I do not blame them for doing that. It just demonstrates how natural this interpretation is and how unnatural it is to stick to an ordinal interpretation only. It may strike some as strange that happiness would be bounded from below and/or above, as response scales like " $1, \ldots, 10$ " or "very bad, ..., excellent" seem to suggest. However, in reality we have never met a respondent who, when faced with the question to evaluate his happiness on a $(0,10)$-scale, would refuse to answer because his happiness level, being a "12" was not included in the scale presented. Each respondent accepts and understands a finite scale, 
where the lower bound stands for "Complete Misery" and the upper bound for "Perfect Bliss".

Similarly, it is interesting to consider the inequality of the happiness distribution. Let us continue this simple two-person example. We define inequality simply by the standard deviation of happiness. In this case the standard deviation is 0.5 . It is easily seen that it does not change if we add one unit to both evaluations. Therefore, let us apply another simple transformation to the happiness responses. Let us now square the happiness indicator yielding 36 and 49 as happiness values. The average is 42.5 and the standard deviation becomes 6.5. It is obvious: aggregates, averages and inequality measures make no sense if we do not assume cardinality to begin with.

Also happiness data do not give much support for the analysis of redistribution problems, if we stick to the ordinal interpretation. Let us assume an ordinal utility function $U\left(y, f_{s}\right)$, which increases in income $y$. Two individuals $A$ and $B$ have utilities $U_{A}=U\left(y_{A}, f_{s_{A}}\right)$ and $U_{B}=U\left(y_{B}, f_{s_{B}}\right)$, respectively. Now one thing is sure, the ordinal interpretation ensures that we may redistribute the sum income such that both individuals get the same utility by solving the equation $U_{A}=U\left(y_{A}-\Delta y, f_{S_{A}}\right)=U\left(y_{B}+\Delta y, f_{s_{B}}\right)=U_{B}$ under the provision that redistributed incomes are positive. The individuals $A$ and $B$ are then on the same indifference curve. However, apart from this utility equalization we cannot make any statement, if we do not admit for the cardinal interpretation. If we would redistribute by $\Delta y$ but fall short of equalization, we cannot say whether the utility loss of $A$ $U\left(y_{A}, f_{s_{A}}\right)-U\left(y_{A}-\Delta y, f_{s_{A}}\right)$ is greater or smaller than the utility gain $U\left(y_{B}+\Delta y, f s_{B}\right)-U\left(y_{B}, f s_{B}\right)$ of $B$. The net aggregate effect of any redistribution cannot be assessed.

The obvious solution is to accept the cardinal significance of subjective self-evaluations of happiness or satisfaction as meaningful. Or more directly, if a respondent evaluates his happiness by a "6" or an " 8 ", we have to accept that answer as his or her degree of happiness. It implies that we accept a transition from 6 to 7 or from 7 to 8 to stand for equal improvements of happiness.

Is this such a strange assumption? In my eyes not. In the first place it is a question of semantics, and common culture. Language is a common good, created in an evolutionary way in order to have a means of communication between people. That is, words represent (roughly) the same meaning to all in the language community. We all believe that happiness is bounded from below by a state of absolute despair (not necessarily to be equalized with death) and from above by a state of perfect happiness or "bliss". It follows that it is natural that evaluations will be on a bounded scale like school grades, e.g. from 0 to 10 or their 
verbal equivalents "very bad" to "excellent", used in many schools as well. And in the same way the most efficient way to use the gradations in between, is to assume that each subsequent grade stands for an equal jump on the ladder between 0 and 10 .

What is the difference between this cardinal satisfaction concept and the shunned concept of cardinal utility in consumer theory? The difference is that from the observation of purchasing or more generally choice behaviour we cannot derive cardinal information (revealed preferences), while satisfaction questions provide that information, however inaccurately (stated preferences). There is no mystery about how it is done either. It is just a repeatable question module yielding a straightforward answer.

This is just the same method as is used in physics for some centuries, when measurement units and methods are developed to measure electrical currents, light intensity, temperature and so on. It is evident that there is some arbitrariness involved in how to translate the phenomenon in terms of a specific scale, but after that choice has been made the measurement unit gets a life of its own. By its usage it gains significance and after some time the results get a common language meaning, just as the strength of an electric current is described in Volts for the technician, or the dioptre for an individual wearing glasses. For instance Wikipedia defines:

A dioptre is a unit of measurement of the optical power of a lens or curved mirror, which is equal to the reciprocal of the focal length measured in metres (i.e. 1/metres). For example, a 3 dioptre lens brings parallel rays of light to focus at $1 / 3$ metre.

Quantifying a lens in terms of its optical power rather than its focal length is useful because when relatively thin lenses are placed close together their powers approximately add. Thus a thin 2 dioptre lens placed close to a thin 0.5 dioptre lens yields almost the same focal length as a 2.5 dioptre lens would have....

We see here exactly the same procedure: the unit of measurement is defined by some observation. The usefulness of this particular choice is then explained because the observation, so measured, is handsome to use in important calculations where an (approximately) additive law holds.

Transferring the argument to the measurement of happiness we see that there is nothing arbitrary in the measurement of happiness by survey questions. It is a well-defined empirical operation. If we accept it, the way is open to defining averages, inequalities and evaluating redistributions, in short to the use of happiness or satisfaction calculus for normative social policy. The only thing we have to accept is that our measurements are less exact and more volatile over time than physical measurements. Hence, it is easier and more reliable to make statements 
on the average happiness of a population of individuals, where the measurement errors will compensate each other, than to make statements about a single individual.

\section{A glance at the political usage of cardinal satisfaction}

As shown before, if we accept the assumption of interpersonal ordinal comparability, there are a lot of relevant socio-economic applications in the field of equivalence scales. However, if we also accept the assumption of cardinality, there opens up a new world. Happiness of individuals is defined by a measurable and repeatable operation, where the measurement does not depend in any way on the observer. It is an objective measurement. That is, if the response categories are $1,2,3, \ldots, 10$ it is assumed that all respondents scale their happiness between 0 and 10 and that all respondents evaluate the adjacent jumps between categories as equal. Clearly, this assumption cannot be proven to be true in an empirical way. This could only be validated in an objective way, if we had an alternative way of measuring individual "happiness". However, "happiness" as such is a metaphysical concept. It becomes a physical concept only by defining it by means of an empirical measurement method. The outcome of such measurements should not depend on the person who measures and it should yield (roughly) the same outcomes in repeated measurements. Last but not least the measurement outcomes should fit our predictions more or less. The first two requirements are obviously met. Whether the third requirement is met is a matter of taste. If most people feel it is met, it does.

There is one point of confusion that is frequently raised. How is it possible that one individual evaluates a specific situation as "extremely satisfactory", while another individual evaluates the same situation as "extremely unsatisfactory"? Is this not tantamount to saying that the happiness-meter is extremely unreliable and unstable? The answer to this apparent paradox is that each individual evaluates situations in his own way, given his personal situation, his past experiences, his social environment, etc. We would only have a problem if two very similar persons would evaluate the same situations differently. Fortunately, this is not the case. It is also therefore, that a systematic explanation of satisfaction answers is possible, yielding statistically significant effects.

If we assume that a cardinal interpretation is meaningful, we may think of new applications.

The first result is that we can produce a social happiness atlas of a society. See the society as a landscape of persons. The co-ordinates are social characteristics like age, education, region of the country, civil status, 
income, political party, employment status, etc. For each point on the map we get an altitude co-ordinate, standing for "happiness" or satisfaction with life. We may also think of several co-ordinates standing for several domain satisfactions. We refer to Van Praag, Frijters and Ferrer-i-Carbonell (2003), where it is shown that happiness with life as a whole may be seen as an aggregate of domain satisfactions. It follows that the policy maker gets an idea of how happiness is distributed over society, and how domain satisfactions are distributed as well. As he may estimate the impact of various policies on individual satisfactions, this gives also the key to formulating policies that may enhance the happiness of groups of individuals or of the society as a whole. As measures generally will favour some citizens and worsen the position of other citizens, it becomes also possible to get some idea of a Kaldor compensation in terms of increments and decrements of happiness. We refer especially to Kapteyn and Van Herwaarden (1980), who studied the effect of changing tax schedules on the distribution of financial satisfaction, taking into account reference and adaptation effects. In short, this is a fascinating piece of information for any policy maker.

Aggregation of individual happiness would also lead to an index for Gross National Happiness (see also, Kahneman 2004). In essence this is the Benthamite Social Welfare Function (SWF).

Then the government's objective might be to maximize this social welfare function. However, there is a problem here: the weighting problem. Should everybody be weighted equally or should for example the poor be over-weighted in the SWF? It is well-known that the SWF may be defined more generally by the use of weights as $\mathrm{SWF}=\sum_{n} w_{n} U_{n}$ or still more generally as $\mathrm{SWF}=W\left(U_{1}, \ldots, U_{N}\right)$. Each individual or each social group gets its own weight. We see that knowledge of the individual happiness levels does not give automatically a happiness index for policy makers(See also, Frey and Stutzer (2005)). Here is a political value judgement required about the functional specification of the SWF. Needless to say that political parties as a rule will embrace different SWF-specifications.

However, there are several less ambitious objectives where the new apparatus can play a significant role.

The first field is poverty analysis. If we define everybody as poor if his $U<\alpha$, where $\alpha$ is a cutoff-point, either chosen by policy makers or by means of a survey by the population concerned, then we can estimate how many individuals or households are poor in society and, what is very important, we can identify the poor according to their social co-ordinates. The value of $\alpha$ may be taken to equal 4 ("bad") on a 10-scale or less severely 5 . This is the so-called subjective poverty approach. We refer to the first contribution in this line by Goedhart et al. (1977) and for a multi-dimensional domain satisfaction approach to Van Praag and 
Ferrer-i-Carbonell (2007). Hence, we get a poverty map of society and this is helpful for policy, because policy measures can become better targeted. First with respect to social coordinates, that is, which specific groups need help and can be effectively supported? Second, because we can differentiate help with respect to life-domains. Some are "health-poor", because their health satisfaction is low, and need more health care or health cost subsidy. Others are "job-poor" and need better working conditions. Again, others are feeling financially poor and need more income support.

The second field is the impact assessment of political measures on various social segments. If we know the determinants of satisfaction and happiness and the government changes the values of those determinants, then we are also able to assess the impact of such changes in terms of individualized happiness gains and losses and changes in (subjective) poverty gaps.

Up to now the reader may have got the idea that the measurement of happiness and satisfaction is only relevant for policy makers. However, this is by no means true. The third field deals with more commercial applications. We think on the cardinal measurement of self-rated satisfaction with health. Changes in health can be assessed in terms of "health gains" and "health gains per dollar" (Van Praag and Ferrer-iCarbonell 2004; Dolan and Kahneman 2006). This is clearly not only relevant for the shaping of health policy, but also for pharmaceutical firms, health insurance companies, and all other kinds of health agents and authorities. In modern countries the value of therapies and medicines has to be assessed in order to get them in the insured package. Therefore a cost-benefit analysis is needed, that takes account of the costs and labour productivity effects. However, an important dimension of the benefits is the so-called intangible benefits. These are frequently neglected or estimated in a somewhat arbitrary way. For instance, by assigning a value of $\$ 100000$ to each healthy life year. How much better feels the patient and perhaps his family really? Here the subjective measurement is coming in the picture. This cost-benefit assessment (including the intangibles) may also be applied to subgroups of the population, differentiated according to age, health risk profiles, or specific diseases.

Similarly, job satisfaction evaluations may be used as a tool for evaluating personnel policy. Another field of application might be establishing the money value of health injuries and the corresponding damage amounts to be paid.

It lies at hand to apply the methodology in marketing analysis. We may measure in the same way the satisfaction with a car, a house or peanut butter. This may give indications to marketeers how to direct their selling efforts and/or to model the product materially or in image. 
Then it is only one step to define descriptions of real products and fictitious ones by means of vignettes to be evaluated by respondents in surveys or in a laboratory situation. Notice that the latter evaluations are based on ex ante utility conceptions.

\section{Conclusion}

At the moment we see in the circles of some economists still a certain reluctance to recognize the significance of the happiness economics methodology, and especially to admit for a cardinal significance of satisfaction questions. This is no doubt the result of half a century of cursing cardinalism. It is our prediction that in the next decade the measuring of cardinal utility or satisfaction by means of satisfaction questions will become a matter of routine. Obviously, the extension to normative policy via the admission of cardinalist interpretations will not devalue the ordinal usage for compensation questions, etc. The admission of cardinalism is an extension of the methodology for new objectives, not a substitution of one method for another.

This implies that the methodology of what is now called "happiness economics" probably will become one of the major instruments of socio-economic policy. At the moment we stand just at the beginning.

\section{References}

Blanchflower, D.G. and A.J. Oswald (2004), "Well-Being over Time in Britain and the USA", Journal of Public Economics 88, 1359-1386.

Boes S., M. Lipp and R. Winkelmann (2007), "Money Illusion under Test", forthcoming in Economics Letters.

Brickman, P. and D.T. Campbell (1971), "Hedonic Relativism and Planning the Good Society", in M.H. Apley, eds., Adaptation-Level Theory: A Symposium, Academic Press, NY, pp. 287-302.

Clark, A.E. and A.J. Oswald (1994), "Unhappiness and Unemployment", Economic Journal 104, 648-659.

Clark, A.E., A.J. Oswald and P.B. Warr (1994), "Is Job Satisfaction U-shaped in Age?", CEPREMAP Working Paper No. 9407.

Clark, A.E. and A.J. Oswald (2002), "A Simple Statistical Model for Measuring How Life Events Affect Happiness", International Journal of Epidemiology 31, 1139-1144.

Clark, A.E., P. Frijters and M.A. Shields (2006), "Income and Happiness: Evidence, Explanations and Economic Implications", Working Paper No. 2006-24, Paris-Jourdan Sciences Economiques. 
Deaton, A.S. and J. Muellbauer (1986), "On measuring Child Costs: With Applications to Poor Countries", Journal of Political Economy 94, 720-744.

Di Tella, R., R.J. MacCulloch and A.J. Oswald (2001), "Preferences over Inflation and Unemployment: Evidence from Surveys of Happiness", American Economic Review 91(1), 335-341.

Di Tella, R. and R. MacCulloch (2006), "Some Uses of Happiness Data in Economics", Journal of Economic Perspectives 20(1), 25-46.

Dolan P. and D. Kahneman (2006), "Interpretations of Utility and their Implications for the Valuation of Health", Working Paper 2006, Tanaka Business School, Imperial College, London.

Easterlin, R. (1974), “Does Economic Growth Improve the Human Lot?", in P.A. David and M.W. Reder, eds., Nations and Households in Economic Growth: Essays in Honor of Moses Abramovitz, Academic Press, Inc., New York.

Ferrer-i-Carbonell, A. and B.M.S. Van Praag (2002), "The Subjective Costs of Health Losses due to Chronic Diseases: An Alternative Model for Monetary Appraisal", Health Economics 11, 709-722.

Ferrer-i-Carbonell, A. and P. Frijters (2004), "How Important Is Methodology for the Estimates of the Determinants of Happiness?", Economic Journal 114(497), 641-659.

Ferrer-i-Carbonell, A. (2005), "Income and Well-Being: An Empirical Analysis of the Comparison Income Effect", Journal of Public Economics 89(5-6), 997-1019.

Frey, B.S. and A. Stutzer (2000), "Happiness, Economy and Institutions", Economic Journal 110, 918-938.

Frey, B.S. and A. Stutzer (2002), "What can Economists Learn from Happiness Research?', Journal of Economic Literature 40(2), 402-35.

Frey, B., S. Luechinger and A. Stutzer (2004), "Calculating Tragedy: Assessing the Costs of Terrorism”, Working Paper, Zurich.

Frey, B. and A. Stutzer (2005), "National Indicators of Well-Being: A View from Political Economy", presented at Annual Meeting of the European Public Choice Society, December 2005.

Goedhart, Th., V. Halberstadt and A. Kapteyn (1977), “The Poverty Line: Concept and Measurement", The Journal of Human Resources 12, 503-520.

Houthakker, H.S. (1950), "Revealed Preference and the Utility Function", Economica 17, New Series, 159-174. 
Houthakker, H.S. (1961), "The Present State of Consumption Theory", Econometrica 29, 704-740.

Kahneman, D., P.P. Wakker and R. Sarin (1997), "Back to Bentham? Explorations of Experienced Utility", Quarterly Journal of Economics 112, 375-405.

Kahneman, D. (2004), "Toward National Well-Being Accounts", American Economic Review 94(2), 429-434.

Kapteyn, A. and B.M.S. Van Praag (1976), "A New Approach to the Construction of Family Equivalence Scales", European Economic Review 7(4), 313-335.

Kapteyn A. (1977), A Theory of Preference Formation, PhD Thesis, Leyden University.

Kapteyn, A. and F.G. van Herwaarden (1980), "Interdependent Welfare Functions and Optimal Income Distribution", Journal of Public Economics 14, 375-397.

Layard, R. (2005), Happiness, Allen Lane, London.

Luttmer, E.F.P. (2005), "Neighbors as Negatives: Relative Earnings and Well-Being", Quarterly Journal of Economics 120(3), 963-1002.

Pareto, V. (1909), Manuel d'économic politique, Paris: Giard \& Brière.

Robbins, L. (1935), An Essay on the Nature \& Significance of Economic Science, 2nd edition. MacMillan, London (first edition 1932).

Samuelson, P.A. (1947), Foundations of Economic Analysis, Harvard University Press, Cambridge, USA.

Senik, C. (2004), "When Information Dominates Comparison: Learning from Russian Subjective Panel Data", Journal of Public Economics 889-10, 2099-2123.

Senik, C. (2005), "Income Distribution and Well-Being: What can we Learn from Subjective Data?", Journal of Economic Surveys 19, 43-63.

Van Praag B.M.S. (1968), Individual Welfare Functions and Consumer Behavior - A Theory of Rational Irrationality, North-Holland Publishing Company Amsterdam, Contributions to Economic Analysis, nr. 57.

Van Praag, B.M.S. (1971), "The Welfare Function of Income in Belgium: an Empirical Investigation", European Economic Review 2, 337-369.

Van Praag, B.M.S. (1976), "The Individual Welfare Function and its Offspring", in J.S. Cramer et al. eds., Relevance and Precision, North-Holland Publishing Company, Amsterdam, pp. 263-293.

Van Praag, B.M.S., A. Kapteyn and F.G. van Herwaarden (1979), "The Definition and Measurement of Social Reference Spaces", The Netherlands' Journal of Sociology 15, 13-25. 
Van Praag, B., Th. Goedhart and A. Kapteyn (1980), "The Poverty Line a Pilot Survey in Europe", The Review of Economics and Statistics 62(3), 461-465.

Van Praag, B.M.S. and N.L. van der Sar (1988), "Household Cost Functions and Equivalence Scales", Journal of Human Resources 23, 193-210.

Van Praag B.M.S. (1991,1994), "Ordinal and Cardinal Utility: An Integration of the Two Dimensions of the Welfare Concept" Journal of Econometrics 50, 69-89. Also published in R. Blundell, I. Preston, I. Walker eds., The Measurement of Household Welfare, Cambridge University Press, pp. 86-110.

Van Praag, B.M.S. (1993), "The Relativity of the Welfare Concept", in A. Sen and M. Nussbaum, eds., Quality of Life, Clarence Press, Oxford.

Van Praag, B.M.S. and M.F. Warnaar (1997), "The Cost of Children and the Use of Demographic Variables in Consumer Demand", in O. Stark and M.R. Rosenzweig eds., Handbook of Population and Family Economics, vol. 1A, Elsevier Science, Amsterdam, pp. 241-273.

Van Praag, B.M.S. and P. Frijters (1999), "The Measurement of Welfare and Well-Being; the Leyden Approach", in D. Kahneman, E. Diener and N. Schwarz, eds., Well-Being: The Foundations of Hedonic Psychology, Russell Sage Foundation, New York, pp. 413-433.

Van Praag, B.M.S. and P. Frijters (1999), "Different Data Sources for Studying Behaviour", in M.G. Fase and W. Kanning, eds., Economics, Welfare Policy and the History of Economic Thought: Essays in Honour of Arnold Heertje, Cheltenham, UK, pp. 290-309.

Van Praag, B.M.S., P. Frijters and A. Ferrer-i-Carbonell (2003), "The Anatomy of Subjective Well-Being", Journal of Economic Behavior and Organization, 51, 29-49.

Van Praag, B.M.S. and A. Ferrer-i-Carbonell (2004), Happiness Quantified: A Satisfaction Calculus Approach, Oxford University Press, Oxford and New York.

Van Pragg, B.M.S. and B. Baarsma (2005), "Using Happiness Surveys to Value Intangibles: The Case of Airport Noise", Economic Journal 115 224-246.

Van Praag, B.M.S. and A. Ferrer-i-Carbonell (2007), "The Subjective Approach to Multidimensional Poverty Measurement", in N. Kakwani and J. Silber, eds., Quantitative Approaches to Multidimensional Poverty Measurement, Palgrave Macmillan. 